\title{
ESTUDIO EXPLORATORIO SOBRE APRENDIZAJE NO FORMAL E INFORMAL DE ESTUDIANTES Y EGRESADOS UNIVERSITARIOS ${ }^{1}$
}

\author{
Rosario Carrasco, Fabiola Jadue, Mario Letelier, \\ Claudia Oliva ${ }^{2}$
}

\begin{abstract}
RESUMEN
Existe consenso en que el aprendizaje no formal e informal debe ser reconocido por su impacto en los conocimientos y habilidades adquiridas. Este estudio pretende aportar al conocimiento del aprendizaje no formal e informal universitario, para ello se utilizó una metodología mixta, se analizaron factores que lo impulsan, y su uso y contribución al logro de resultados de aprendizaje en una universidad de nuestro país. A partir de los hallazgos del estudio, se elaboran una serie de sugerencias tentativas para la gestión universitaria para relevar el aprendizaje no formal e informal universitario.
\end{abstract}

Palabras clave: aprendizaje informal, aprendizaje no formal, resultados de aprendizaje, gestión universitaria, aseguramiento de la calidad

\section{EXPLORATORY STUDY ABOUT INFORMAL AND NON- FORMAL LEARNING IN STUDENTS AND UNIVERSITY GRADUATES}

\section{ABSTRACT}

There seems to be consensus regarding the need of recognition of non-formal and informal learning, given its impact in the acquisition of knowledge and skills. The present study is aimed to provide an analysis of university students' non-formal and informal learning. By using a mixed-method approach, it analyzed factors behind non-formal and informal learning as well as the use and contribution of this learning to achieve specific learning outcomes at a Chilean university. It provides suggestions for improving the university's capacity to enhance non-formal and informal learning.

Keywords: informal learning, non-formal learning, learning outcomes, university management, quality assurance

1 Este estudio fue financiado con recursos de la Vicerrectoría Académica de la Universidad de Santiago de Chile.

2 Centro de Investigación en Creatividad y Educación Superior - CICES. Universidad de Santiago de Chile. Santiago. Chile. Contacto: rosario.carrasco.benavente@gmail.com 


\section{ESTUDIO EXPLORATORIO SOBRE APRENDIZAJE NO FORMAL E INFORMAL DE ESTUDIANTES Y EGRESADOS UNIVERSITARIOS}

\section{Introducción}

La OCDE, en su informe Terms, concepts and models for analysing the value of recognition programmes (2007a), enfatiza la necesidad del reconocimiento de los sistemas de aprendizaje no formal e informal. En este mismo documento se aclara que si bien este reconocimiento no crea habilidades y competencias, el otorgar visibilidad a este aprendizaje podría tener un fuerte impacto en el uso que las personas puedan hacer de estas habilidades.

Entre los beneficios derivados de este reconocimiento se señalan:

- facilitar la detección de las brechas entre habilidades existentes y esperadas en el país u organización;

- utilizar como herramienta para planificar actividades de capacitación y aprendizaje;

- mejorar la autoestima en la medida que se adquiere conciencia de los conocimientos y habilidades;

- mejorar la distribución de calificaciones de la población;

- evitar que las personas comiencen sus estudios desde cero y promover el aprendizaje durante la vida, que facilitaría una aproximación más ajustada de las trayectorias de enseñanza y aprendizaje;

- mejorar la empleabilidad de los postulantes y perspectivas de movilidad de los que trabajan;

- reducir los tiempos de estudio requerido para otorgar la calificación del sistema formal, usualmente utilizado como una vía de ingreso al sistema de educación terciaria.

No obstante, Werquin (2008), y el mismo informe OCDE mencionado anteriormente, señalan que aunque pareciera haber 
consenso en cuanto a que las personas adquieren habilidades, conocimientos y competencias fuera del sistema de educación y capacitación formal, y a la necesidad de reconocer o visibilizar este aprendizaje, habría poco o nulo consenso respecto de las definiciones de los términos claves, el valor que se le debiera otorgar a este aprendizaje, quién debiera decidir qué es valioso, y las definiciones de estándares evaluativos de los resultados provenientes de este.

A ello se suma las complejidades que conllevaría el estudio empírico del aprendizaje informal y que ha redundado en una serie de limitantes para su estudio. Una básica se refiere a la dificultad de los mismos sujetos analizados en reconocer el propio aprendizaje informal y, asimismo, en verbalizarlo (Eraut, 2000; Livingstone, 2001). Incluso se llega a señalar que no solo los educadores están ajenos al aprendizaje informal, sino que las personas tampoco están conscientes del propio, siendo aludido como grandes témpanos de hielo sumergidos (Tough, 2002).

Si bien el estudio del aprendizaje no formal e informal ha cobrado especial relevancia con relación a la población adulta, lo que cobra sentido en la medida que el aprendizaje que ocurre en estos contextos representa una valiosa fuente de capital humano (OECD, 2010), se desconocen investigaciones sobre factores, uso y contribución en el ámbito universitario en nuestro país.

Su estudio en este grupo podría proveer mayores elementos para el análisis de la calidad de la educación universitaria: el valor agregado de la formación universitaria y en qué medida los resultados de aprendizaje prioritarios a una institución están asociados al aprendizaje formal y/o al aprendizaje no formal e informal; hacer visible el aprendizaje no formal e informal universitario y crear conciencia entre los estudiantes, académicos y administradores acerca de la magnitud y su aporte en la trayectoria de vida; empoderar a los estudiantes con mejores condiciones de empleabilidad y en otros aspectos de su vida; investigar en qué medida las universidades pueden adecuar la planificación docente y prácticas pedagógicas de manera de aprovechar mejor el aprendizaje 
no formal e informal de los estudiantes, entre otros eventuales beneficios.

Considerando la premisa de que los individuos aprenden a lo largo de toda la vida (Knowles, 1970), y el escaso o inexistente estudio del aprendizaje no formal e informal en el contexto universitario nacional, este artículo espera aportar elementos conceptuales sobre aprendizaje no formal e informal universitario chileno, además de un análisis acerca del uso y contribución al logro de resultados de aprendizaje en una universidad, como también sugerencias tentativas a la gestión universitaria para relevar este aprendizaje.

\section{Revisión de literatura especializada sobre aprendizaje "formal", "no formal" e "informal"}

Las distinciones entre aprendizaje no formal e informal serían relativamente nuevas, fueron introducidas por el Banco Mundial a principios de los 70 y luego popularizadas por Coombs et al. (1973) y Coombs y Ahmed (1974).

Las definiciones han evolucionado en el tiempo, coexistiendo una diversidad de significados asociados a los términos de aprendizaje "formal", "no formal" e "informal" (OCDE, 2007a; Werquin, 2007, 2008), los que incluso se sobreponen unos a otros, generando discrepancias respecto de estos.

En primer lugar, este documento expone una revisión de las definiciones para el aprendizaje "formal", "no formal" e "informal" desde principios de la década de los 70 hasta hoy, con el objetivo de relevar los énfasis e imprecisiones de estos términos. En segundo lugar, se describen algunos estudios empíricos sobre aprendizaje informal realizados en diversos países, limitantes y desafíos que plantea para estudios posteriores. Tercero, se describe la tipología de aprendizaje propuesta por la Organización para la Cooperación y el Desarrollo Económicos, OCDE (2007a). 
Revisión de definiciones de aprendizaje "formal", "no formal" e "informal"

\section{Lo "formal"}

Con relación a la estructura y organización en que ocurre el aprendizaje, destaca el alto grado de estructuración y organización, señalándose como un sistema ordenado jerárquicamente (Coombs et al., 1973), altamente institucionalizado (Schugurensky, 2000), y que ocurre en un contexto organizado y estructurado (CEDEFOP, 2008).

En cuanto al periodo que abarca, se señala que va desde la educación primaria (Coombs et al., 1973) o educación preescolar (Schugurensky, 2000) hasta los estudios de posgrado. Puede ocurrir en una variedad de programas e instituciones especializadas en capacitación técnica y profesional (Coombs et al., 1973; Comunidad Europea, 2000), en un centro de capacitación de adultos o en el lugar de trabajo (OCDE, 2007b).

Es descrito como el aprendizaje conducente al reconocimiento mediante diplomas o calificaciones (Comunidad Europea, 2000; CEDEFOP, 2008, Schugurensky, 2000), en tanto la OCDE (2007b) incluye la posibilidad de otorgar una certificación.

Desde la dimensión de espacio físico en que se desarrolla, puede suceder tanto dentro y fuera de instituciones de educación y capacitación (OCDE, 2007b). Correspondería al aprendizaje designado explícitamente en términos de objetivos, tiempo y recursos (CEDEFOP, 2008). Respecto a la intencionalidad, es indicado como el aprendizaje de carácter intencionado desde el punto de vista del aprendiz (CEDEFOP, 2008).

También, se releva el rol de la autoridad del docente sobre un cuerpo de conocimientos preestablecidos, de acuerdo con lo que se concibe como aquel aprendizaje que sucede cuando un docente tiene la autoridad para determinar que efectivamente se aprenda un currículo de un cuerpo preestablecido de conocimiento (Livingstone, 2000, 2001). 
En contraste con las definiciones anteriores que describen una serie de condiciones asociadas al aprendizaje formal, Eraut (2000) provee una definición más amplia. Para este autor, en vez de reconocer el cumplimiento de un conjunto de condiciones, el cumplimiento de cualquiera de las siguientes es suficiente para considerar el aprendizaje como formal: un marco prescrito de aprendizaje; un evento de aprendizaje organizado; la presencia de un profesor designado; el otorgamiento de una calificación o crédito o; la especificación externa de resultados de aprendizaje.

\section{Lo "informal"}

De acuerdo con Coombs et al. (1973) el término educación informal se referiría al aprendizaje para toda la vida mediante el cual cada individuo adquiere actitudes, valores, habilidades y conocimiento de la experiencia cotidiana y los recursos e influencias educativas en su ambiente, proveniente tanto de la familia, el vecindario, el trabajo, recreación, mercado laboral, la biblioteca y los medios masivos de comunicación.

Definiciones posteriores destacan el carácter no intencionado de este aprendizaje (Comunidad Europea, 2000; OCDE, 2007b y CEDEFOP, 2005, 2008) y por lo mismo, cabe la posibilidad de que no sea reconocido ni siquiera por los mismos individuos como una contribución a su conocimiento y habilidades (Comunidad Europea, 2000).

Respecto del grado de estructura y organización, tanto para la OCDE (2007b) como CEDEFOP (2008) el aprendizaje informal no dispondría de organización ni estructura, sino que provendría de actividades cotidianas recreativas, familiares o de trabajo. Un segundo aspecto enfatizado por estas definiciones se refiere a que no conduciría a certificación (OCDE, 2007b).

En cuanto al espacio físico donde se desarrollaría el aprendizaje informal, Schugurensky (2000) señala que puede ocurrir dentro de instituciones educacionales formales y no formales, pero fuera del currículo de estas instituciones, donde este ocurre de manera independiente y a veces en sentido contrario a las metas intencionadas del currículo explícito. 
Mientras que estas definiciones de aprendizaje informal recalcan el carácter no intencionado, desestructurado y desprovisto de objetivos de aprendizaje, otros autores introducen matices a estas definiciones. En esta línea, ISCED (1997) y EUROSTAT (2001, 2006) conciben al aprendizaje informal como intencionado, pero menos organizado y estructurado que el aprendizaje formal.

Otros autores ofrecen definiciones que conciben diversos grados de intencionalidad y conciencia del aprendizaje informal. Schugurensky (2000), utilizando estos criterios, distingue tres formas de aprendizaje informal: la primera se refiere al aprendizaje autodirigido, entendido como proyectos desarrollados por individuos, tanto independientemente o como parte de un grupo, correspondiendo a un aprendizaje intencionado, donde se está consciente de que se ha aprendido algo; la segunda forma de aprendizaje informal se refiere al aprendizaje incidental, que sucede cuando el individuo no tenía ninguna intención previa de aprender de una experiencia, pero después de que esta ocurre adquiere consciencia de que ha aprendido algo; y la tercera forma de aprendizaje informal se refiere a la socialización o aprendizaje tácito, que se refiere a la internalización de valores, actitudes, comportamientos y habilidades que ocurren en la vida diaria, y que no sería intencionado ni consciente. Livingstone (2001, 2002), en tanto, utiliza el grado de consciencia de la actividad como aprendizaje significativo, como criterio para distinguir entre las prácticas informales explícitas y, por otra parte, las percepciones cotidianas, socialización y otras formas de aprendizaje tácito.

\section{Lo "no formal"}

En cuanto al grado de estructura y organización, es concebido como un aprendizaje organizado (Coombs et al., 1973; ISCED, 1997), desarrollado mediante actividades planificadas (CEDEFOP, 2005 y 2008).

Según el nivel de intencionalidad, se refiere a aprendizaje intencionado desde el punto de vista del aprendiz (OECD, 2007b; CEDEFOP, 2008). De acuerdo con el criterio de duración, se desarrollaría mediante programas de corta duración (Schugurensky, 2000). 
Respecto de la presencia de objetivos de aprendizaje se observan discrepancias, ya que mientras para Coombs et al. (1973) constaría de objetivos de aprendizaje, CEDEFOP (2008) lo define como aprendizaje desprovisto de objetivos de aprendizaje.

De acuerdo con el criterio de espacio físico en que se desarrolla el aprendizaje no formal, Coombs et al. (1973) y Schugurensky (2000) señalan que ocurre fuera del sector formal, tanto dentro y fuera de las instituciones educacionales.

En cuanto a la certificación, los distintos autores concuerdan en señalar que no necesariamente se otorgaría una certificación o diploma de asistencia a los aprendizajes desarrollados mediante esta vía (Schugurensky, 2000; Comunidad Europea, 2000; OECD, 2007b, CEDEFOP, 2008) y, según la Comunidad Europea (2000), si bien abarcaría actividades planificadas, estas no serían evaluadas.

Tanto Schugurensky (2000) como Livingstone (2001) resaltan que este aprendizaje no formal tendría un carácter voluntario, y se desarrollaría en presencia de docentes, instructores o facilitadores, haciendo uso de un currículo organizado como cursos o seminariostaller (workshops) de educación de adultos.

Este aprendizaje podría desarrollarse en distintas etapas de la vida en distintos segmentos de la población, mediante múltiples instancias: dependiendo del contexto del país, podrá abarcar desde programas educacionales que imparten alfabetización de adultos, educación básica para niños fuera del sistema escolar, habilidades para la vida, habilidades para el trabajo, y cultura general (ISCED, 1997); y si bien usualmente está dirigida a adultos, niños y adolescentes, también pueden participar de estas instancias mediante, por ejemplo, programas de scouts, cursos de idiomas como segunda lengua, clases de música, entre otros (Schugurensky, 2000).

A diferencia de las anteriores definiciones de aprendizaje no formal, Eraut (2000) se refiere al aprendizaje no formal -para no usar aprendizaje informal- como contraste al aprendizaje formal, el cual consideraría como una categoría residual para describir 
cualquier aprendizaje que no ocurre o no se desprende de un programa formalmente organizado. Distingue tres modalidades de aprendizaje no formal, los cuales pueden variar de acuerdo con el grado de intencionalidad por aprender (variando desde aprendizaje implícito, aprendizaje espontáneo y explícito aunque no planificado, hasta aprendizaje deliberativo) y el timing de los eventos (eventos pasados, actuales o inminentes).

\section{Intento por simplificar la complejidad de definiciones coexistentes}

En un intento por avanzar en el debate sobre aprendizaje formal, no formal e informal, y las discrepancias relativas a los criterios de intencionalidad, objetivos de aprendizaje, y certificación, la OECD (2007a) propone que solamente se utilicen los criterios de objetivos de aprendizaje e intencionalidad para definir el aprendizaje. De acuerdo con esto, se propone la siguiente tipología:

- Aprendizaje formal (la actividad está diseñada con objetivos de aprendizaje y los individuos asisten con la meta explícita de adquirir habilidades, conocimientos o competencias).

- Aprendizaje no formal (los individuos observan o hacen cosas con la intención de adquirir habilidades, conocimientos o competencias).

- Aprendizaje semiformal (los individuos tienen la intención de aprender acerca de algo, y sin saberlo, también aprenden acerca de algo más).

- Aprendizaje informal (individuos aprenden en actividades sin objetivos de aprendizajes y sin saber qué están aprendiendo).

Lo novedoso de esta última clasificación es la introducción del término de aprendizaje semiformal (Werquin, 2007), utilizado para aludir a un tipo cercano al concepto de aprendizaje informal -en cuanto lo que se aprende transciende los objetivos inicialespero que ocurre en el contexto de una actividad de aprendizaje formal. 


\section{Estudios empíricos sobre aprendizaje informal}

Uno de los primeros estudios empíricos en este campo de Johnstone y Rivera (1965), desarrollado a comienzos de la década de los 60, tuvo como objetivo estimar la extensión de actividades de aprendizaje informal entre adultos mediante una encuesta nacional estadounidense. Según este, casi $40 \%$ de los consultados señaló haber realizado estudios por su cuenta sin asistencia de otros. Posteriormente, los estudios de Tough $(1971,1979)$ estuvieron enfocados en las actividades de aprendizaje de adultos más allá del sistema escolar y de programas educacionales. Los hallazgos indicaron que más de dos tercios de los esfuerzos intencionados ocurrían en contextos por completo externos a cursos o programas educacionales institucionalizados (Brookfield, 1981; Brockett y Hiemstra, 1991). En tanto, los estudios de Tough desarrollados a fines de los 60 indicaban que prácticamente todos los adultos estaban de forma regular involucrados en proyectos de aprendizaje autodirigidos y deliberados que trascendían al sistema escolar y programas de capacitación.

Penland (1977) realizó una consulta nacional en Estados Unidos a fines de 1976, cuyos hallazgos señalaban que más de 3/4 de la población de adultos de Estados Unidos estaban involucrados en actividades de aprendizaje autoplanificadas y que dedicaban más de 500 horas anuales a este aprendizaje informal.

En el caso del General Social Survey in Canada aplicado en 1998 (Livingstone, 2001), se incorporó la consulta por el aprendizaje autodirigido en el último mes, mediante la cual se encontró que alrededor de 30 \% de la población del país había estado involucrado en este tipo de aprendizaje y que habrían destinado a ello alrededor de 19 horas mensuales.

También, se ha indagado en el aprendizaje informal en cursos de educación de adultos, como en un estudio finés de 1995 (Blomqvist, Niemi y Ruuskanen, 1998), y una encuesta en el Reino Unido realizada durante 1994-1997 (Beinhart y Smith, 1998). Estas investigaciones mostraron que $22 \%$ de adultos fineses habrían estado involucrados en aprendizaje autodirigido por a lo menos 20 horas 
durante el año en que se realizó el estudio, y que 57\% de adultos británicos habrían estado involucrados en esta forma de aprendizaje durante el año en que se aplicó la encuesta.

La primera encuesta nacional sobre prácticas de aprendizaje informal de adultos en Canadá, desarrollada en 1998 (NALL, 1998; Livingstone, 1999), tuvo por objetivo indagar en la amplia gama de actividades de aprendizaje de adultos, tanto relativas al sistema escolar como cursos de educación continua y aprendizaje informal, que sucedía fuera de la educación organizada, siendo el principal énfasis el estudio de los diversos aspectos de aprendizaje informal intencionado. El principal hallazgo se refería a que los canadienses estarían dedicando una significativa y creciente cantidad de tiempo en actividades de aprendizaje informal por su propia cuenta, lo cual implicaría que estas prácticas debiesen ser relevadas explícitamente para ser integradas en la elaboración de políticas educacionales, económicas y sociales.

\section{Metodología}

Definición operativa de aprendizaje no formal e informal

En este estudio se optó por un análisis conjunto de aprendizaje no formal e informal. Un primer motivo se debe a la confusión de términos conceptuales, como se expuso en la sección anterior. Además, debido al desconocimiento de la existencia o inexistencia de uno de estos tipos de aprendizaje en el ámbito universitario, y su vinculación con los resultados de aprendizajes, se decidió no excluir el análisis de uno u otro (no formal e informal). En términos prácticos, esta utilizó la recomendación de la OCDE (2007), que entiende por investigación no formal e informal todo aquel que no es formal.

\section{Objetivos del estudio}

El objetivo general de este estudio fue explorar el aprendizaje no formal e informal de los estudiantes de la Universidad de Santiago de Chile, tanto para identificar factores que impulsan su desarrollo 
como para analizar su uso y contribución al logro de resultados de aprendizajes. Esto se tradujo en los siguientes objetivos específicos:

1. Identificar factores que impulsan el aprendizaje no formal e informal en esta casa de estudios.

2. Analizar el uso y contribución de diversos espacios, personas y actividades de carácter formal, no formal e informal en el desarrollo de resultados de aprendizajes preestablecidos.

3. Elaborar sugerencias tentativas a la gestión universitaria para visibilizar el aprendizaje no formal e informal entre estudiantes universitarios.

\section{Diseño del estudio}

De acuerdo con los objetivos de este estudio, se consideró una perspectiva metodológica cualitativa y cuantitativa, que contemplara la triangulación entre estos métodos para profundizar el análisis del aprendizaje no formal e informal. Se contempló un diseño exploratorio-descriptivo.

\section{Instrumentos utilizados}

Para lograr una primera aproximación al aprendizaje no formal e informal de estudiantes de esta casa de estudios, se optó por diseñar una pauta de entrevista semiestructurada con el objetivo de recoger la percepción de egresados acerca de los factores que habrían impulsado estos aprendizajes durante la etapa universitaria, la caracterización en términos de espacios, personas y actividades mediante las cuales se desarrollarían, y la contribución al resultado de aprendizajes. Para la selección de los informantes que conformaron el campo de estudio, se utilizaron los siguientes criterios de selección:

- Haber egresado de la Universidad de Santiago de Chile como máximo hace 10 años.

- Haber ejercido o estar ejerciendo su profesión.

- Haber estudiado en jornada diurna.

En cuanto a la indagación cuantitativa, durante el primer semestre del 2009 se diseñó un cuestionario cerrado cuyo objetivo era ahondar en la percepción de estudiantes en los últimos dos años de la carrera respecto de la contribución de una serie de espacios, 
personas y actividades de carácter formal, no formal e informal en la adquisición de una serie preestablecida de resultados de aprendizajes comunes a carreras de diversas áreas disciplinarias. Cada hoja del cuestionario contemplaba: a) una primera sección que consultaba respecto del logro percibido de un resultado de aprendizaje específico y b) una segunda sección que indagaba en la contribución de espacios, personas y actividades en el logro del resultado de aprendizaje consultado. Es decir, se preguntó por cada resultado de aprendizaje -tanto la percepción de logro como la contribución de espacios, personas y actividades- en una hoja separada del cuestionario.

Este instrumento contempló una escala con siete alternativas de respuesta, que abarcaban desde el valor 1 (mínimo) hasta el valor 6 (máximo), y la opción no aplica. En el caso de los resultados de aprendizaje, se les pedía que señalaran, basados en dicha escala, en qué medida consideraban que habían logrado el resultado de aprendizaje consultado en esta institución, y en caso que percibieran no haberlo logrado que indicaran la opción no aplica. En el caso de cada uno de los ítems de espacios, personas y actividades, debían indicar en qué medida cada uno de estos había contribuido al logro del resultado de aprendizaje indagado, y en el caso que no hubieran recurrido a su uso debían marcar la opción no aplica. Se les señaló que solo debían marcar una opción en cada ítem.

En vista de la variedad y complejidad de los resultados de aprendizajes que se pudieran haber desarrollado durante la vida universitaria, se optó por elaborar una selección de estos lo suficientemente representativos de la etapa universitaria de pregrado. Para ello, se consideraron tanto los resultados de aprendizaje señalados por los egresados previamente entrevistados, los aprendizajes explicitados con mayor frecuencia a lo largo de los criterios de evaluación de carreras elaborados por la Comisión Nacional de Acreditación, CNA (entonces CNAP), y lo señalado en el modelo educativo de esta institución, para seleccionar resultados de aprendizajes pertinentes al sello educativo institucional. Se seleccionaron quince resultados de aprendizajes relativos a las categorías de conocimientos, habilidades generales, y actitudes y 
valores reconocidos en el modelo educativo institucional. Estos fueron sometidos a la evaluación de un panel de tres expertos nacionales en educación superior, quienes emitieron juicios acerca de la validez de estos resultados de aprendizajes, y corroboraron que fuesen suficientemente representativos del contexto universitario nacional, y no solo para esta institución. En total, se seleccionaron los siguientes resultados de aprendizajes:

Tabla n. ${ }^{\circ}$ 1. Resultados de aprendizajes consultados

\begin{tabular}{|l|}
\hline Resultados de aprendizajes consultados \\
\hline Categoría Conocimientos: \\
\hline - Adquisición de conocimientos teóricos-conceptuales \\
\hline - Adquisición de idiomas extranjeros (distintos al español) \\
\hline Categoría Habilidades generales: \\
\hline - Habilidad para argumentar y emitir juicios fundados \\
\hline - Habilidad para comunicarse en forma oral y escrita \\
\hline - Habilidad para trabajar en equipo \\
\hline - Habilidad para negociar soluciones y acuerdos \\
\hline - Habilidad para organizar actividades personales \\
\hline - Habilidad para aplicar conocimientos teóricos a la práctica \\
\hline - Habilidad para buscar, integrar, y aplicar permanentemente nuevos conocimientos (autoaprendizaje) \\
\hline - Habilidad para adaptarse a situaciones nuevas \\
\hline \\
\hline Categoría Actitudes y valores: \\
\hline - Adquirir cultura general \\
\hline - Actuar con principios éticos \\
\hline - Ejercer derechos y deberes ciudadanos \\
\hline - Relacionarse con personas diversas \\
\hline - Perseverar en el cumplimiento de metas personales \\
\hline
\end{tabular}

Los resultados de la indagación con egresados de la misma universidad fueron utilizados para identificar tres dimensiones de aprendizaje analizados en la encuesta: espacios, personas y actividades. Para cada dimensión se elaboraron ítems con connotación formal, no formal e informal y que se describen a continuación: 
Tabla n. ${ }^{\circ}$ 2. Ítems según dimensión

\begin{tabular}{|l|l|l|}
\hline \multicolumn{3}{|c|}{ Dimensión } \\
\hline Espacios & Personas & Actividades \\
\hline sala de clases & $\begin{array}{l}\text { profesores y/o ayudantes de } \\
\text { esta universidad }\end{array}$ & actividades curriculares de la universidad \\
\hline $\begin{array}{l}\text { espacios de ejercicios } \\
\text { prácticos }\end{array}$ & $\begin{array}{l}\text { funcionarios y/o auxiliares de } \\
\text { esta universidad }\end{array}$ & $\begin{array}{l}\text { participación en investigaciones y proyectos } \\
\text { externos al plan de estudios }\end{array}$ \\
\hline $\begin{array}{l}\text { bibliotecas de la } \\
\text { universidad }\end{array}$ & $\begin{array}{l}\text { compañeros y/o amigos de } \\
\text { carrera o universidad }\end{array}$ & $\begin{array}{l}\text { hacer ayudantías y/o clases dentro o fuera de la } \\
\text { universidad }\end{array}$ \\
\hline $\begin{array}{l}\text { otros lugares en la } \\
\text { universidad }\end{array}$ & $\begin{array}{l}\text { amigos externos a la } \\
\text { universidad }\end{array}$ & $\begin{array}{l}\text { actividades artísticas, culturales y deportivas } \\
\text { organizadas por la universidad u otra entidad }\end{array}$ \\
\hline $\begin{array}{l}\text { otros lugares fuera } \\
\text { de la universidad }\end{array}$ & $\begin{array}{l}\text { la familia } \\
\text { actividades organizadas por los estudiantes }\end{array}$ \\
\hline & $\begin{array}{l}\text { atros actores externos a la } \\
\text { instituciones de educación }\end{array}$ & $\begin{array}{l}\text { trabajo interno o externo a la universidad, ya sea } \\
\text { pagado o no }\end{array}$ \\
\hline & $\begin{array}{l}\text { actividades formativas de interés personal en } \\
\text { entidades externas a la universidad }\end{array}$ \\
\hline & actividades desarrolladas en forma autodidacta \\
\hline & $\begin{array}{l}\text { actividades de socialización con amigos y } \\
\text { familiares }\end{array}$ \\
\hline
\end{tabular}

Con una primera versión preliminar del cuestionario se realizó una entrevista grupal a seis egresados que, en ese momento, se desempeñaban en distintos cargos en la misma universidad. Se les solicitó responder el cuestionario, y posteriormente, se discutieron aspectos críticos en cuanto a la validez de constructo; la capacidad autoexplicativa de los ítems de espacios, personas y actividades, y la claridad del formato para responder. Específicamente, esta entrevista fue esencial para evaluar la pertinencia de los ítems de espacios, personas y actividades, así como detectar ítems relevantes que hubiesen sido omitidos del cuestionario. A partir de sus comentarios, se validaron los ítems de estas tres dimensiones y se ajustó el lenguaje utilizado de manera que facilitara la claridad en la comunicación con los estudiantes a encuestar.

\section{Muestra y recolección de datos}

En total, se realizaron quince entrevistas a egresados hombres y mujeres de diversas facultades, cuya descripción se detalla a continuación: 
Tabla n. ${ }^{\circ}$ 3. Distribución de egresados entrevistados según facultad

\begin{tabular}{|c|c|}
\hline Número de entrevistas a egresados & Facultad \\
\hline 3 & Ciencias Médicas \\
\hline 3 & Química y Biología \\
\hline 3 & Humanidades \\
\hline 3 & Ciencias \\
\hline 3 & Ingeniería \\
\hline
\end{tabular}

Estas entrevistas se aplicaron durante los meses de agosto y septiembre del 2008, y la duración osciló entre 60 y 90 minutos. En todos los casos se solicitó el consentimiento informado de los entrevistados, quienes lo expresaron por escrito.

En cuanto a la encuesta, se decidió aplicar la versión definitiva a estudiantes de los últimos dos años de la carrera, bajo el supuesto que habrían acumulado más experiencias universitarias en comparación a los de primeros años. Se optó por una modalidad de muestreo no probabilística por conglomerados. El instrumento se aplicó durante el segundo semestre de 2009 a alumnos de las carreras de ingeniería civil química, ingeniería civil industrial, ingeniería civil mecánica, enfermería, psicología, contador auditor, y en ingeniería en física. Se decidió aplicarla en más de una carrera, ya que debido a la cantidad y diversidad de especialidades en esta institución, se estimó conveniente cautelar por la representatividad de estas en la muestra recolectada. La distribución se expone en la siguiente tabla:

Tabla n. ${ }^{\circ}$ 4. Distribución de estudiantes encuestados según carrera

\begin{tabular}{|l|c|}
\hline Carrera & Cantidad de encuestas respondidas \\
\hline Ingeniería civil industrial & 36 \\
\hline Ingeniería civil mecánica & 27 \\
\hline Ingeniería civil química & 29 \\
\hline Ingeniería en física & 6 \\
\hline Contador auditor & 29 \\
\hline Psicología & 31 \\
\hline Enfermería & 46 \\
\hline Total & 204 \\
\hline
\end{tabular}

A partir de la tabla anterior, se puede apreciar que la muestra obtenida varió notoriamente en el caso de ingeniería física, del área ciencias exactas, en el cual solamente se lograron seis encuestas respondidas. Esto es un claro indicativo de problemas de cobertura 
en la muestra obtenida, y de las limitantes de este estudio para realizar comparaciones de resultados según el área disciplinaria del estudiante, que pudiesen proveer comparaciones según este criterio de análisis.

Aunque un instrumento de este tipo no se había aplicado antes, se decidió emplear la modalidad presencial durante horario de clases para responder dudas de los estudiantes. El tiempo de aplicación varió entre 20 y 45 minutos. La longitud de la encuesta fue un impedimento para que mayor cantidad de profesores accedieran a aplicar este instrumento en sus horarios de asignatura, lo que redundó en la reducida muestra obtenida (204 casos) sobre la esperada (565 casos). El universo respectivo se estimó en alrededor de 1.800 estudiantes de los últimos dos años de la carrera en modalidad diurna.

En cuanto a la confiabilidad del instrumento, el coeficiente Alpha de Cronbach fue considerado bueno 0,993 sobre la totalidad de los ítems de la encuesta. En virtud de que en ingeniería física solo se obtuvieron 6 respuestas, se decidió eliminarlas para fines de análisis de resultados. Finalmente, se obtuvo un total de 198 cuestionarios respondidos.

\section{Análisis de datos}

Con relación a las entrevistas a egresados, estas se analizaron mediante sistema de codificación abierta sugerida por Strauss y Corbin (1990) para la identificación de términos y categorías, y posterior vinculación entre conceptos.

Respecto de las encuestas aplicadas a estudiantes de los últimos dos años de la carrera, se utilizó un análisis estadístico descriptivo, de acuerdo con lo cual se priorizó el análisis de frecuencias, porcentajes y tablas de contingencia, sin aplicación de pruebas de hipótesis, en vista del carácter exploratorio de este estudio y de la reducida muestra obtenida.

Se elaboraron índices sumativos para cada uno de los ítems consultados de espacios, personas y actividades, de manera de analizar el uso y contribución de cada uno de los ítems en el logro de los distintos resultados de aprendizajes indagados. A modo de ejemplo, a 
partir de los quince ítems de sala de clases se obtuvo el índice general de uso de la sala de clases en el logro de resultados de aprendizajes. A continuación se expone el estadístico Alpha de Cronbach obtenido para cada uno de los índices de uso e índices de contribución de espacios, personas y actividades:

Tabla n. ${ }^{\circ}$ 5. Coeficiente Alpha de Cronbach para los índices de uso e índices de contribución de los ítems de espacios, personas y actividades.

\begin{tabular}{|l|c|c|}
\hline & $\begin{array}{c}\text { Alpha de Cronbach } \\
\text { para índice de uso }\end{array}$ & $\begin{array}{c}\text { Alpha de Cronbach para } \\
\text { indice de contribución }\end{array}$ \\
\hline Dimensión espacios & & 0,890 \\
\hline sala de clases & 0,615 & 0,844 \\
\hline espacios de ejercicios prácticos & 0,868 & 0,898 \\
\hline bibliotecas de la universidad & 0,855 & 0,873 \\
\hline otros lugares en la universidad & 0,896 & 0,869 \\
\hline otros lugares fuera de la universidad & & 0,876 \\
\hline Dimensión personas & 0,560 & 0,893 \\
\hline profesores y/o ayudantes de esta universidad & 0,962 & 0,862 \\
\hline funcionarios y/o auxiliares de esta universidad & 0,625 & 0,852 \\
\hline compañeros y/o amigos de carrera o universidad & 0,886 & 0,843 \\
\hline amigos externos a la universidad & 0,713 & 0,850 \\
\hline la familia & 0,943 & 0,939 \\
\hline actores de otras instituciones de educación & 0,943 & 0,865 \\
\hline otros actores externos a la universidad. & & 0,937 \\
\hline Dimensión actividades & 0,683 & 0,928 \\
\hline actividades curriculares de la universidad & 0,980 & 0,900 \\
\hline $\begin{array}{l}\text { participación en investigaciones y proyectos } \\
\text { externos al plan de estudios }\end{array}$ & 0,911 \\
\hline $\begin{array}{l}\text { hacer ayudantías y/o clases dentro o fuera de la } \\
\text { universidad }\end{array}$ & 0,986 & 0,879 \\
\hline $\begin{array}{l}\text { actividades artísticas, culturales y deportivas } \\
\text { organizadas por la universidad u otra entidad }\end{array}$ & 0,962 & 0,914 \\
\hline actividades organizadas por los estudiantes & 0,974 & \\
\hline trabajo interno o externo a la universidad, ya sea \\
pagado o no & 0,964 & \\
\hline $\begin{array}{l}\text { actividades formativas de interés personal en } \\
\text { entidades externas a la universidad }\end{array}$ & 0,960 & \\
\hline actividades desarrolladas en forma autodidacta & 0,914 & \\
\hline actividades de socialización con amigos y familiares & 0,858 & \\
\hline otras actividades externas a la universidad & 0,955 & \\
\hline
\end{tabular}

A partir de lo anterior, si bien el resultado de este coeficiente tiende a fluctuar desde 0,8 o más, hay índices que obtienen un coeficiente más bajo, como el de uso de profesores y/o ayudantes, 
de uso de espacios de ejercicios prácticos, y el de uso de compañeros y/o amigos de carrera o universidad, lo cual denota que se debe tener cautela con el análisis e interpretación de sus resultados.

Para simplificar la exposición de resultados, los índices sumativos fueron transformados en variables categóricas mediante la creación de rangos. En el caso de los índices de uso, se dividieron en tres tercios: muy utilizados (tercio superior); algo utilizados (tercio intermedio); y poco utilizadas (tercio inferior). Para los índices de contribución se dividieron en los siguientes tercios: alta contribución (tercio superior); mediana contribución (tercio intermedio); y baja contribución (tercio inferior).

\section{Principales hallazgos de las entrevistas a egresados}

Factores que impulsan el aprendizaje no formal y aprendizaje informal

Entre los factores que impulsan la búsqueda y desarrollo de aprendizaje informal se identificaron factores asociados al desempeño académico de los estudiantes, la búsqueda por aportar a la calidad de vida de sectores pobres o aislados, la recreación y distensión de los estudiantes, y la canalización de demandas estudiantiles.

\section{Factores académicos}

Según los relatos de los entrevistados, tanto las carencias del plan de estudio como el apoyo de los docentes a los estudiantes para explorar intereses de índole académico por cuenta propia, habrían constituido factores que impulsaron el desarrollo de aprendizaje no formal e informal.

Al referirse a las carencias del plan de estudio, se señaló a la ausencia o débil incorporación de enfoques o teorías de conocimiento, al distanciamiento de los académicos en su vinculación con los estudiantes, y a las restricciones en infraestructura y recursos de apoyo, como limitantes curriculares que propiciaron una fuerte motivación para la búsqueda autónoma de estrategias de aprendizaje. Se destacó la relevancia de formar grupos de estudio y apoyarse 
mutuamente con los compañeros a lo largo de la carrera, lo cual habría sido fundamental para persistir en sus estudios, adquirir conocimientos teórico-conceptuales y comprender enfoques que estarían ausentes o débilmente incorporados en los planes de estudios correspondientes:

"Por iniciativa propia participé en un grupo de estudio, porque me gustaba esa área de la psicología, y poco pasaban de eso en la escuela" (psicología).

“... juntarse a estudiar se daba mucho en mi carrera porque los ramos eran muy difíciles. La mayoría fomentaba el trabajo en equipo como herramienta de aprendizaje, se logró un trabajo en equipo, pero no sé si con esa intención de parte del cuerpo docente" (licenciatura en química).

En cuanto a la motivación provista por uno o más docentes a los estudiantes por profundizar intereses de índole académico, destaca la semejanza entre la figura de este académico y la de un mentor, señalándose la importancia que ejerció en su formación la influencia de un académico que los habría impulsado a "ir más allá" del plan de estudios. Según palabras de un entrevistado:

"Se notaba que amaba enseñar, el tema que le dijeras que querías investigar él lo encontraba interesante y te daba datos de dónde investigar. La diferencia él la potenciaba, lo cual es súper bueno" (periodismo).

Entre las actividades desarrolladas a partir del apoyo del profesor para indagar en intereses académicos que podían ir más allá de las actividades del plan de estudios, se mencionaron la participación en proyectos o investigaciones liderados por académicos del programa, presentación de estudios en congresos, realización de ayudantías o clases, las cuales no pertenecían o bien eran adicionales al plan de estudios.

Además de motivar a los estudiantes para desarrollar actividades externas al plan de estudios, y a interrogar y reflexionar sobre el aprendizaje formal, estos docentes se caracterizarían por 
establecer relaciones cercanas con los estudiantes, estableciendo vínculos de confianza que trascendían a la sala de clases mediante conversaciones y/o encuentros fuera de ella, y que incluso seguían cultivándose una vez que habían egresado de la carrera. Al respecto, se señaló:

"Me fui al ramo con este otro profesor y establecí con él una relación súper cercana, de pronto iba a la sala y conversábamos, cosa que hasta el día de hoy, a mi parecer no pasa tanto en estos ramos... después él mismo fue mi profesor guía, y de hecho para el magíster le pedí recomendaciones" (licenciatura en computación).

Tanto en el caso del aprendizaje no formal e informal impulsado a partir de carencias curriculares percibidas por los entrevistados, como en el aprendizaje no formal e informal facilitado por el apoyo de uno o más docentes para desarrollar actividades de indagación académica por cuenta propia, estos estarían configurados a partir del aprendizaje formal, ya sea por sus debilidades (teóricas-conceptuales, infraestructura, académicos y otros recursos) o fortalezas (apoyo de académicos que ejercían fuerte rol de mentores).

\section{Factores personales}

A partir de las entrevistas también se identificó que otra motivación para el aprendizaje no formal e informal provendría de la motivación personal por aportar a la calidad de vida de sectores sociales desaventajados. Esta se habría expresado en el emprendimiento de actividades externas al plan de estudio, mediante acciones de voluntariados o comunitarias, como también mediante acercamiento de un área disciplinaria (física o química, por ejemplo) a sectores pobres o alejados geográficamente:

"Cuando había paros de la salud o la campaña de invierno (de salud) nos pedían si queríamos ir a ayudar de forma voluntaria a los SAPU, y ahí se trabaja desde una perspectiva más humana" (enfermería).

"Fuimos un grupo de estudiantes a llevar la ciencia a lugares donde no se tiene mucho... Esto fue iniciativa 
de un grupo en particular que de ahí llamó a unirse y formó un grupo como de cuarenta personas que fuimos para allá con el patrocinio de la USACH, y auspicio de una Fundación que hay acá en la facultad" (licenciatura en química).

Si bien se señalaron como actividades que emergen de la motivación intrínseca de los estudiantes y sus grupos de pares, es difícil escindirlas de su base disciplinaria. En este sentido, podemos hablar de actividades externas pero que han sido concebidas al alero de actividades del plan de estudios.

\section{Factores de socialización y distensión}

Otro factor asociado al desarrollo de aprendizaje no formal e informal provendría de la búsqueda por vincularse con compañeros de diversas unidades académicas, para lograr una apertura hacia diversos puntos de vista y distensión en la rutina estudiantil.

Esta necesidad se habría resuelto, en algunos casos, mediante la participación en actividades coprogramáticas de carácter deportivo, artísticas y culturales adicionales a la cantidad mínima exigida como requisito de egreso, en ese momento, en las carreras de pregrado, indicándose que si bien en un principio realizaron estos cursos obligatorios, organizados por la institución, terminaron participando por interés personal en cursos adicionales a los exigidos. Los egresados hicieron hincapié en el aporte de estas actividades para liberar tensiones con relación a las dificultades o carga académica de la carrera, señalándolo como una instancia en que lograban expresarse en algo ajeno a estas y, asimismo, en que compartían con compañeros de otras carreras, lo que les permitía conocer diversos puntos de vista. Según una entrevistada:

"Aprendí sobre todo en pintura porque me encanta, me ayudó a enfocar como hobby la pintura y me ayudó para liberar tensiones, es una forma de expresarte que no sea de lo que estás trabajando o haciendo.... Aprendí a compartir con los otros, con personas de distintos pensamientos, de diversas carreras" (licenciatura en bioquímica). 
Otro tipo de actividad mediante la cual se propició la socialización y distensión se refiere a las actividades culturales, tales como asistencia a recitales, charlas, foros y debates, y también actividades recreativas en áreas verdes con grupos de pares dentro de la universidad. Más que una motivación explícita por participar en ellas, los entrevistados habrían aprovechado estas oportunidades ya que eran muy accesibles para estudiantes que compartían en un mismo campus universitario, y que facilitaban mucho la posibilidad de congregar a estudiantes de diversas carreras y facultades, expresándose:

"En los pastos se da una dinámica muy especial... uno conocía a gente de otras carreras y facultades, conocía otros puntos de vista, teníamos largas conversaciones y debates de política, religión, hasta metafísica" (ingeniería en geomensura).

\section{Factores asociados a necesidades del alumnado}

Otro eje desde el cual se desarrollaría el aprendizaje no formal e informal correspondería a la búsqueda por canalizar demandas e inquietudes estudiantiles. La participación en centros de alumnos y, en general, en movimientos estudiantiles, serían instancias mediante las cuales los estudiantes intentarían dar respuesta a problemas específicos de la carrera (derivados de limitaciones de recursos, por ejemplo), de la institución, o bien, del escenario universitario nacional, indicándose lo siguiente:

"Yo fui delegada de mi carrera y representé a varios que no les daban créditos, iba a hablar con los académicos, con los encargados y como que eso igual me marcó bastante como profesional, encuentro que siempre es mejor conversar las cosas que hacer más desorden" (ingeniería física).

"Desde el primer año me llamó la atención todo el tema de la lucha estudiantil, iba a las marchas, esa vez estuve en unos comités de la facultad de humanidades porque la idea era participar en bloque, participé por mi carrera" (traducción inglés-japonés). 


\section{Resultados de la encuesta aplicada a estudiantes de carreras de la Universidad de Santiago de Chile}

Percepción de estudiantes encuestados acerca de resultados de aprendizajes desarrollados durante la etapa universitaria

Gráfico n. ${ }^{\circ}$ 1. Percepción de logro de resultados de aprendizajes consultados, en una escala de 1 a 6

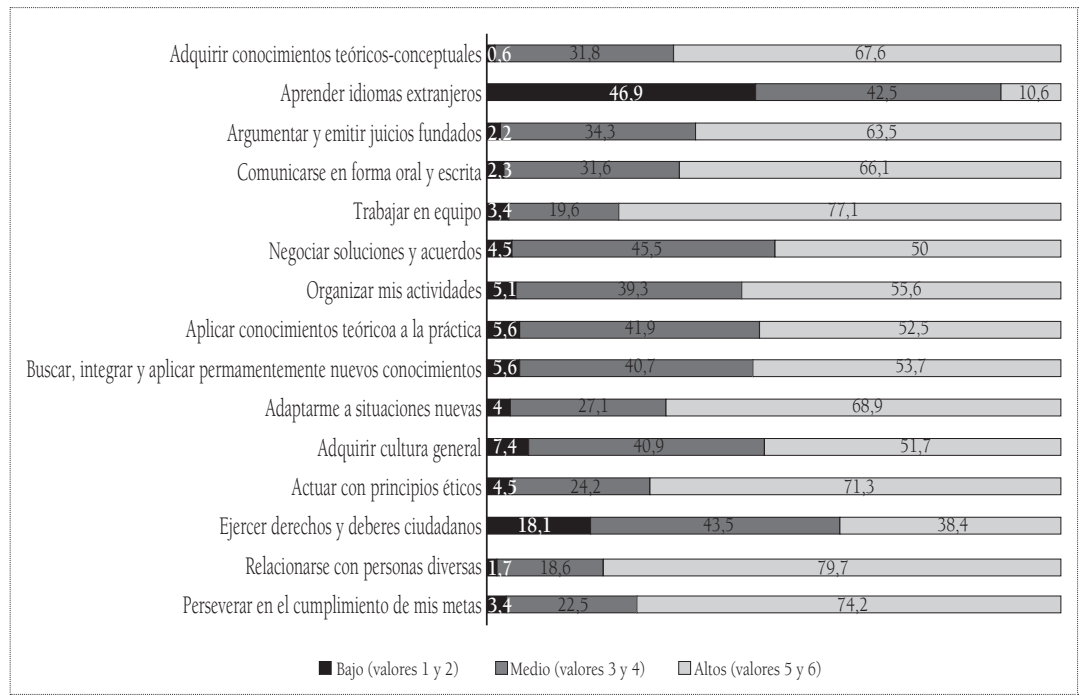

Se observa un mayor porcentaje de los estudiantes encuestados que perciben haber logrado la capacidad para relacionarse con personas diversas $(79,7 \%)$, trabajar en equipo $(77,1 \%)$, perseverancia en el cumplimiento de metas personales $(74,2 \%)$, actuar con principios éticos $(71,3 \%)$ y adaptarse a situaciones nuevas $(68,9 \%)$. En cuanto a los resultados de aprendizajes menos logrados, se identifica la capacidad para aprender idiomas extranjeros $(10,6 \%)$, ejercer derechos y deberes ciudadanos (38,4\%), en cuyos casos menos de la mitad de los encuestados considera haber desarrollado estas capacidades. 
Percepción de los encuestados de ítems de espacios, personas y actividades utilizados para el logro de los resultados de aprendizaje consultados

Gráfico n. ${ }^{\circ} 2$. Uso de espacios, personas y actividades consultadas

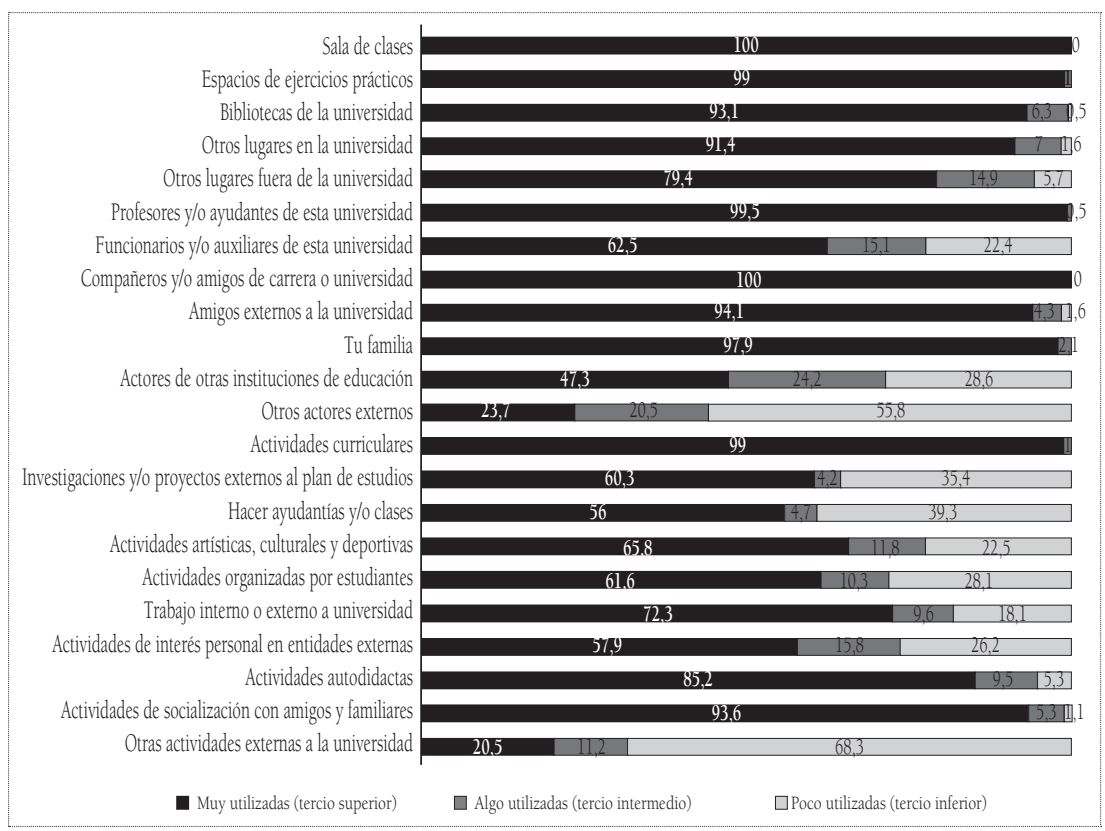

A partir de los índices de uso de personas, espacios y actividades, se observa que el uso de la sala de clases, espacios de ejercicios prácticos, profesores y/o ayudantes de la universidad, compañeros y/o amigos de carrera o universidad, y actividades curriculares son señalados por $99 \%$ de los encuestados como recursos muy utilizados en el desarrollo de los resultados de aprendizajes consultados. A su vez, estos recursos se vincularían con el contexto de aprendizaje formal asociado al plan de estudios de la carrera.

Destaca una segunda serie de ítems que fueron señalados por más de $75 \%$ de los encuestados como de alto uso, correspondientes a otros lugares fuera de la universidad; bibliotecas de la universidad, otros lugares en la universidad, amigos externos a la universidad, la familia, actividades de socialización con amigos y familiares, y actividades autodidactas. A partir de estos últimos, es posible 
identificar la alusión a uso de ítems de corte formal y, asimismo, no formal e informal. La alta mención de otros lugares fuera de la universidad pudiese estar vinculada en gran medida al estudio o realización de actividades asociadas al plan de estudios, en el hogar del estudiante o el hogar de compañeros.

Percepción de los encuestados de la contribución de ítems de espacios, personas y actividades utilizados para el logro de los resultados de aprendizaje consultados

Gráfico n. ${ }^{\circ}$ 3. Contribución de espacios, personas y actividades utilizadas

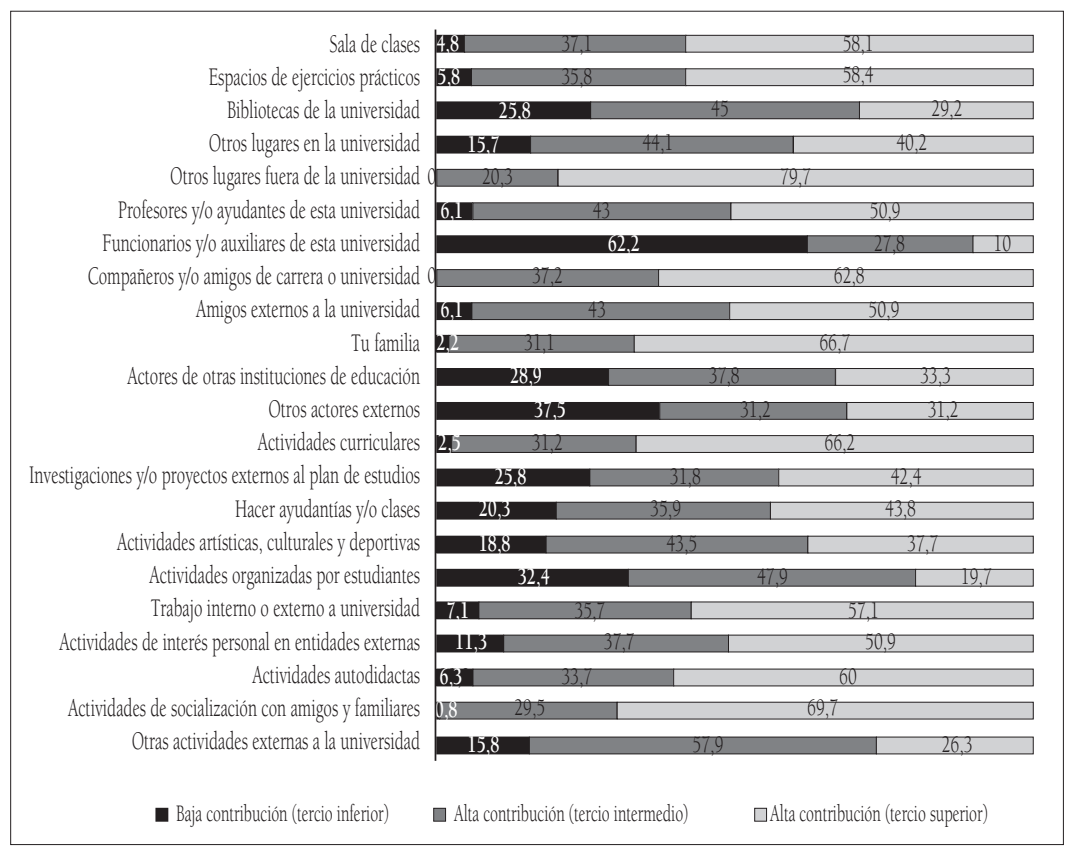

Se observa que, entre los estudiantes que han hecho uso de los recursos indagados, el ítem con mayor porcentaje de alta contribución en el logro de los resultados de aprendizajes consultados corresponde a otros lugares fuera de la universidad $(79,7 \%)$. Como se señaló más arriba, esta percepción pudiese estar asociada principalmente al estudio o realización de actividades vinculadas al plan de estudios en la propia casa o en la de compañeros. 
Entre $60 \%$ y $70 \%$ de los estudiantes destacan el aporte de personas, espacios y actividades con connotación formal (actividades curriculares, sala de clases, espacios de ejercicios prácticos, profesores y/o ayudantes, compañeros y/o amigos de carrera o universidad), y con connotación no formal e informal (actividades de socialización, actividades autodidactas, la familia, amigos externos, trabajo, y actividades de interés personal en entidades externas).

\section{Comparación de los cinco ítems más utilizados entre los cinco resultados de aprendizajes más logrados}

Tabla n. ${ }^{\circ}$ 6. Ítems más utilizados en logro de resultados de aprendizajes más logrados

\begin{tabular}{|c|c|c|c|c|c|}
\hline & \multicolumn{5}{|c|}{ Resultados } \\
\hline & $\begin{array}{l}\text { Relacionarse con } \\
\text { personas diversas }\end{array}$ & $\begin{array}{l}\text { Trabajar en } \\
\text { equipo }\end{array}$ & $\begin{array}{l}\text { Perseverar en el } \\
\text { cumplimiento de } \\
\text { metas personales }\end{array}$ & $\begin{array}{c}\text { Actuar con } \\
\text { principios éticos }\end{array}$ & $\begin{array}{c}\text { Adaptarse a } \\
\text { situaciones nuevas }\end{array}$ \\
\hline $\begin{array}{l}\text { Primer } \\
\text { ítem }\end{array}$ & $\begin{array}{c}\text { Compañeros y/o } \\
\text { amigos de carrera } \\
\text { o universidad } \\
(100,0 \%)\end{array}$ & $\begin{array}{l}\text { Sala de clases } \\
(100,0 \%)\end{array}$ & $\begin{array}{l}\text { Tu familia } \\
(100,0 \%)\end{array}$ & Tu familia $(99,2 \%)$ & $\begin{array}{c}\text { Profesores y/o } \\
\text { ayudantes de } \\
\text { esta universidad } \\
(98,4 \%)\end{array}$ \\
\hline $\begin{array}{l}\text { Segundo } \\
\text { ítem }\end{array}$ & $\begin{array}{l}\text { Tu familia } \\
(100,0 \%)\end{array}$ & $\begin{array}{c}\text { Espacios de } \\
\text { ejercicios prácticos } \\
(100,0 \%)\end{array}$ & $\begin{array}{c}\text { Compañeros y/o } \\
\text { amigos de carrera } \\
\text { o universidad } \\
(98,5 \%)\end{array}$ & $\begin{array}{c}\text { Sala de clases } \\
(97,6 \%)\end{array}$ & $\begin{array}{c}\text { Compañeros y/o } \\
\text { amigos de carrera } \\
\text { o universidad } \\
(98,4 \%)\end{array}$ \\
\hline $\begin{array}{l}\text { Tercer } \\
\text { ítem }\end{array}$ & $\begin{array}{l}\text { Sala de clases } \\
(100,0 \%)\end{array}$ & $\begin{array}{c}\text { Compañeros y/o } \\
\text { amigos de carrera } \\
\text { o universidad } \\
(100,0 \%)\end{array}$ & $\begin{array}{l}\text { Profesores y/o } \\
\text { ayudantes de } \\
\text { esta universidad } \\
(97,7 \%)\end{array}$ & $\begin{array}{l}\text { Profesores y/o } \\
\text { ayudantes de } \\
\text { esta universidad } \\
(97,6 \%)\end{array}$ & $\begin{array}{c}\text { Actividades } \\
\text { curriculares } \\
(98,4 \%)\end{array}$ \\
\hline $\begin{array}{c}\text { Cuarto } \\
\text { ítem }\end{array}$ & $\begin{array}{c}\text { Espacios de } \\
\text { ejercicios prácticos } \\
(98,6 \%)\end{array}$ & $\begin{array}{c}\text { Profesores y/o } \\
\text { ayudantes de } \\
\text { esta universidad } \\
(99,3 \%)\end{array}$ & $\begin{array}{c}\text { Amigos externos } \\
\text { a la universidad } \\
(97,7 \%)\end{array}$ & $\begin{array}{c}\text { Compañeros y/o } \\
\text { amigos de carrera } \\
\text { o universidad } \\
(97,6 \%)\end{array}$ & $\begin{array}{l}\text { Sala de clases } \\
(97,5 \%)\end{array}$ \\
\hline $\begin{array}{l}\text { Quinto } \\
\text { ítem }\end{array}$ & $\begin{array}{c}\text { Otros lugares en } \\
\text { la universidad } \\
(98,6 \%)\end{array}$ & $\begin{array}{c}\text { Actividades } \\
\text { curriculares } \\
(99,3 \%)\end{array}$ & $\begin{array}{c}\text { Actividades } \\
\text { curriculares } \\
(97,7 \%)\end{array}$ & $\begin{array}{c}\text { Actividades } \\
\text { curriculares } \\
(97,6 \%)\end{array}$ & $\begin{array}{c}\text { Espacios de } \\
\text { ejercicios prácticos } \\
(97,5 \%)\end{array}$ \\
\hline
\end{tabular}

Al percibir los espacios, personas y actividades más utilizados por estudiantes que autoperciben un alto logro en estos cinco resultados de aprendizajes, se observan que algunos ítems son mencionados reiteradamente con un alto grado de uso. Este es el caso de los profesores y/o ayudantes, compañeros y/o amigos de carrera o universidad, actividades curriculares, y sala de clases (mencionados en cuatro resultados de aprendizajes); y espacios de ejercicios prácticos y la familia del estudiante (señalados en tres resultados de aprendizajes). 
Entre los espacios, personas y actividades más utilizados en los distintos resultados de aprendizajes, destaca la referencia al contexto de aprendizaje formal, entendiéndose por ello a los espacios de sala de clases y espacios de ejercicios prácticos, las figuras de profesores y/o ayudantes, compañeros y/o amigos de carrera o universidad, y actividades curriculares.

\section{Comparación de los cinco ítems de mayor contribución entre los cinco resultados de aprendizajes más logrados}

Tabla n. ${ }^{0}$. Ítems que más contribuyen a logro de resultados de aprendizajes más logrados

\begin{tabular}{|c|c|c|c|c|c|}
\hline & \multicolumn{5}{|c|}{ Resultados } \\
\hline & Relacionarse con & $\begin{array}{c}\text { Trabajar en } \\
\text { equipo }\end{array}$ & Perseverar en & $\begin{array}{l}\text { Actuar con } \\
\text { principios }\end{array}$ & Adaptarse a \\
\hline $\begin{array}{c}\text { Primer } \\
\text { ítem }\end{array}$ & $\begin{array}{c}\text { Otros lugares fuera } \\
\text { de la universidad } \\
(92,4 \%)\end{array}$ & $\begin{array}{c}\text { Espacios de } \\
\text { ejercicios prácticos } \\
(93,5 \%)\end{array}$ & $\begin{array}{c}\text { Tu familia } \\
(92,4 \%)\end{array}$ & $\begin{array}{c}\text { Tu familia } \\
(91,3 \%)\end{array}$ & $\begin{array}{c}\text { Otros lugares fuera } \\
\text { de la universidad } \\
(83,2 \%)\end{array}$ \\
\hline $\begin{array}{l}\text { Segundo } \\
\text { ítem }\end{array}$ & $\begin{array}{c}\text { Otros lugares en } \\
\text { la universidad } \\
(91,4 \%)\end{array}$ & $\begin{array}{c}\text { Compañeros y/o } \\
\text { amigos de carrera } \\
\text { o universidad } \\
(91,3 \%)\end{array}$ & $\begin{array}{c}\text { Otros lugares fuera } \\
\text { de la universidad } \\
(88,1 \%)\end{array}$ & $\begin{array}{c}\text { Otros lugares fuera } \\
\text { de la universidad } \\
(90,2 \%)\end{array}$ & $\begin{array}{c}\text { Trabajo interno } \\
\text { o externo a la } \\
\text { universidad } \\
(79,8 \%)\end{array}$ \\
\hline $\begin{array}{l}\text { Tercer } \\
\text { ítem }\end{array}$ & $\begin{array}{c}\text { Compañeros y/o } \\
\text { amigos de carrera } \\
\text { o universidad } \\
(90,1 \%)\end{array}$ & $\begin{array}{c}\text { Actividades } \\
\text { curriculares } \\
(87,6 \%)\end{array}$ & $\begin{array}{l}\text { Actividades de } \\
\text { socialización } \\
(79,5 \%)\end{array}$ & $\begin{array}{l}\text { Profesores y/o } \\
\text { ayudantes de } \\
\text { esta universidad } \\
(83,1 \%)\end{array}$ & $\begin{array}{c}\text { Actividades } \\
\text { curriculares } \\
(74,2 \%)\end{array}$ \\
\hline $\begin{array}{c}\text { Cuarto } \\
\text { ítem }\end{array}$ & $\begin{array}{l}\text { Actividades de } \\
\text { socialización } \\
(88,5 \%)\end{array}$ & $\begin{array}{c}\text { Otros lugares fuera } \\
\text { de la universidad } \\
(80,3 \%)\end{array}$ & $\begin{array}{l}\text { Actividades } \\
\text { autodidactas } \\
(77,8 \%)\end{array}$ & $\begin{array}{c}\text { Actividades de } \\
\text { socialización } \\
(78,2 \%)\end{array}$ & $\begin{array}{c}\text { Compañeros y/o } \\
\text { amigos de carrera } \\
\text { o universidad } \\
(70,8 \%)\end{array}$ \\
\hline $\begin{array}{c}\text { Quinto } \\
\text { ítem }\end{array}$ & $\begin{array}{c}\text { Amigos externos } \\
\text { a la universidad } \\
(87,6 \%)\end{array}$ & $\begin{array}{c}\text { Otras actividades } \\
\text { externas a la } \\
\text { universidad } \\
(74,3 \%)\end{array}$ & $\begin{array}{c}\text { Amigos externos } \\
\text { a la universidad } \\
(76,6 \%)\end{array}$ & $\begin{array}{l}\text { Otros actores } \\
\text { externos } \\
(78,0 \%)\end{array}$ & $\begin{array}{l}\text { Actividades de } \\
\text { socialización } \\
(69,6 \%)\end{array}$ \\
\hline
\end{tabular}

A diferencia de los ítems más utilizados entre los aprendizajes más logrados -en que se observan ítems asociados principalmente al contexto de aprendizaje formal- los que contribuyen en mayor medida al logro de estos resultados de aprendizaje tienen relación tanto con el contexto de aprendizaje formal como con el no formal e informal.

Destaca que el ítem relativo a otros lugares fuera de la universidad es mencionado como una alta contribución al logro de los cinco resultados de aprendizajes más logrados. Esto podría estar asociado -como se mencionó antes-al estudio en casa del estudiante 
o de compañeros y, en este sentido, se podría referir a una actividad asociada al aprendizaje formal que se desarrolla en espacios externos a la institución universitaria.

Las actividades de socialización con amigos y familiares también es mencionado como un ítem que contribuye al logro de cuatro de estos resultados de aprendizajes, constatándose la contribución de aprendizaje informal al logro de estos resultados de aprendizaje. También se menciona la contribución de compañeros y/o amigos (tres oportunidades), actividades curriculares, amigos externos a la universidad, y la familia del estudiante (dos oportunidades cada ítem).

Asimismo, se observa una mayor diversidad de ítems que contribuyen al logro de estos resultados de aprendizajes con relación a los más utilizados, señalándose además actividades autodidactas, trabajo interno o externo a la universidad, y otras actividades externas, los cuales referirían a actividades informales o no formales.

\section{Síntesis de hallazgos del estudio}

Tanto mediante las entrevistas a egresados como las encuestas a estudiantes se expresa la valoración otorgada a la adquisición de resultados de aprendizajes en su paso por la universidad. Mientras que los egresados se refirieron al desarrollo de aprendizajes vinculados a la adquisición de conocimientos asociados a la disciplina, aspectos actitudinales-valóricos, y habilidades profesionales; los estudiantes encuestados perciben que en su estadía en la universidad estarían logrando un mayor desarrollo de la capacidad para relacionarse con personas diversas, trabajar en equipo, perseverar en el cumplimiento de las metas, y actuar con principios éticos.

Se constata la relevancia de actividades ligadas al plan de estudios en el desarrollo de los aprendizajes logrados, lo que se puede observar a partir de los ítems más utilizados en el logro de resultados de aprendizajes señalados por los encuestados (sala de clases, espacios de ejercicios prácticos, profesores y ayudantes, compañeros y amigos de carrera o universidad). Cabe relevar la alta contribución de lugares 
fuera de la universidad, lo cual podría estar asociado al estudio o realización de actividades del plan de estudios en casa propia o de compañeros.

Aun cuando ningún entrevistado cuestiona la relevancia de lo aprendido mediante las actividades del plan de estudios, se hizo hincapié en que lo aprendido a partir de estas, podría adquirir mayor sentido mediante actividades no formales o informales. Este rol del aprendizaje no formal e informal señalado por los egresados entrevistados también se pudo observar a partir de la contribución asignada por los encuestados a ítems no formales e informales en el desarrollo de resultados de aprendizajes, como las actividades de socialización con amigos y familiares, actividades autodidactas, actividades de trabajo, y rol de la familia.

Se puede señalar una diversidad de factores que impulsan el desarrollo de aprendizaje no formal e informal (mejorar desempeño académico, calidad de vida de otros, socialización y distensión, resolver necesidades estudiantiles), lo cual es concordante con estudios sobre aprendizaje informal que denotan una variedad de motivos por los cuales se emprenden estas actividades (Livingstone, 2001).

Más allá del o los factores que impulsen este aprendizaje, los adquiridos (o no adquiridos) mediante actividades del plan de estudios pueden ser decisivos en impulsar actividades no formales e informales, como es el caso de los grupos de estudios, participación en proyectos investigativos, o actividades de divulgación disciplinaria, por ejemplo, lo cual se podría asociar al aprendizaje semiformal señalado por Werquin (2007).

Se observa la contribución de actividades no formales e informales que pueden transcurrir tanto al interior de la institución universitaria como en espacios externos a esta, lo que es concordante con lo señalado por la literatura especializada en cuanto el aprendizaje no formal e informal puede ocurrir tanto dentro o fuera de la institución educacional (Schugurensky, 2000). También, se caracterizaría por desarrollarse en conjunto con diversos actores internos y externos a la universidad (compañeros, profesores, amigos, familia), en lo que 
sobresale la importancia otorgada a la interacción con compañeros en el desarrollo de diversas actividades no formales e informales de diversa índole. Si bien los egresados entrevistados no hicieron referencia a actividades autodidactas -lo que ha sido analizado reiteradamente en estudios como una modalidad de aprendizaje informal (Johnstone y Rivera, 1965; Penland, 1977; Tough, 1971, 1979)- fueron mencionadas por los estudiantes encuestados como contribuciones al logro de resultados de aprendizajes. Respecto de la estructura y organización, se observa que se puede albergar actividades con diversos niveles de estructuración, variando desde proyectos comunitarios, investigativos o ayudantías hasta actividades de socialización (donde estas últimas son referidas inequívocamente por la literatura como aprendizaje informal). No obstante, a partir de las entrevistas realizadas no fue posible caracterizar el grado de intencionalidad, lo que es un criterio de análisis muy discutido en la literatura especializada (CEDEFOP, 2005, 2008; Comunidad Europea, 2000; ISCED, 1997; EUROSTAT, 2001, 2006; OCDE, 2007a, 2007b; Schugurensky, 2000).

Las actividades de aprendizaje no formal e informal no se relacionarían con el desarrollo de un resultado de aprendizaje específico sino que la participación de estas actividades podría potenciar un desarrollo de aspectos actitudinales-valóricos (respetar a personas con diversos puntos de vista, por ejemplo), habilidades profesionales (trabajar en equipo, comunicarse con otros, gestionar recursos, etcétera), o bien, conocimientos teóricos-conceptuales ligados a la disciplina (fortalecidos mediante grupos de estudio, por ejemplo).

\section{Recomendaciones tentativas para la gestión universitaria}

A partir de la recurrente mención de ítems de carácter no formal e informal en el logro de los resultados de aprendizajes universitarios, se sugiere la necesidad de asignar valor a estos.

Asimismo, se sugiere la necesidad de reconocer la complejidad para discernir dónde comienza y termina el aprendizaje formal o el 
aprendizaje no formal e informal, ya que más que concebir contextos binarios de aprendizaje, los resultados aquí obtenidos sugieren un flujo continuo entre lo formal e informal. En este sentido, el concepto de aprendizaje semiformal puede ser mayormente indagado, de modo de identificar prácticas de aprendizaje no formal e informal que emanan directamente desde el aprendizaje formal (como lo relatado en las entrevistas a egresados).

Una recomendación que emana directamente del cuestionario utilizado es la necesidad de indagar con mayor detenimiento en el uso de espacios fuera de la universidad, ya que fue mencionado como un ítem altamente utilizado y de alta contribución en los resultados de aprendizaje. No obstante, no se logró recabar mayor información acerca de cuáles lugares fuera de la universidad serían utilizados para estos efectos ni los tipos de actividades desarrollados (ni tampoco la modalidad presencial o virtual de estas).

Puesto que este fue un estudio realizado en una sola institución, surge la necesidad por comparar el aprendizaje no formal e informal entre universitarios de diversas instituciones, con el fin de analizar diferencias o similitudes en los resultados obtenidos relativos a las prácticas de aprendizaje desarrolladas y el peso que le asignan en el logro de resultados de aprendizajes para identificar eventuales aspectos genéricos o específicos de aprendizaje no formal e informal. Este tipo de estudio debiese considerar la posibilidad de controlar según áreas disciplinarias; género, edad, entre otras variables.

Si bien este estudio indagó entre estudiantes y egresados, no se puede desconocer que son perfiles cualitativamente distintos, por lo cual sería recomendable realizar estudios de panel, que permitan conocer la evolución del aprendizaje no formal e informal desde el momento en que el estudiante ingresa (o antes incluso) hasta que egresa (o, en su defecto, abandona sus estudios). En este sentido, el diseño y aplicación de instrumentos para las distintas fases de vida universitaria pudiesen ser utilizadas.

Debido a que se desconoce el valor agregado del aprendizaje no formal e informal en el contexto universitario, surge la inquietud 
sobre cómo visibilizar el aprendizaje no formal e informal para efectos de procesos de mejoramiento continuo y evaluación de la calidad de la educación universitaria. Por ejemplo, mediante los procesos de acreditación de carreras se pudiera dar cuenta del valor agregado del aprendizaje no formal e informal a la calidad académica de estas, y también en qué medida las mismas carreras apoyan e impulsan el aprendizaje no formal e informal en los estudiantes. En esta misma línea, sería recomendable revisar los perfiles de egreso y planes de estudios de carreras con el objetivo de evaluar el rol que desempeña el aprendizaje no formal e informal en el desarrollo de resultados de aprendizajes asumidos por la carrera. Este tipo de evaluación pudiese aportar elementos diagnósticos para retroalimentar al plan de estudio y prácticas de evaluación de aprendizaje utilizadas, como por ejemplo, mediante la identificación de resultados de aprendizaje que se logran en actividades vinculadas al plan de estudios o, en su defecto, logradas en actividades no formales e informales.

Establecido el rol que se espera de los profesores en la formación de los universitarios, se sugiere lograr mayor conocimiento acerca del grado de conciencia de los mismos sobre su propio aprendizaje no formal e informal, valoración que le asignan en la docencia universitaria, su percepción sobre el aprendizaje no formal e informal de los estudiantes, y cómo incentivan este aprendizaje entre estos. Este tipo de análisis pudiese aportar oportunidades para revisar y, si fuese necesario, actualizar prácticas pedagógicas.

Por último, cabe abrir la discusión acerca de cómo lograr una vinculación eficaz con los sectores productivos con el objetivo de evaluar eventuales ajustes en la articulación con el sistema de capacitación y calificación, de manera de incrementar la efectividad de las medidas de este sistema, especialmente de reconocimiento de aprendizajes previos, y proveer condiciones para incrementar el capital humano de esta sociedad.

\section{Referencias bibliográficas}

Beinhart, S.; Smith, P. (1998). National Adult Learning Survey 1997. Sudbury, Suffolk: Department for Education and Employment. Research Report n. ${ }^{\circ} 49$. 
Blomqvist, I.; Niemi, H.; Ruuskanen, T. (1998). Participation in Adult education and training in Finland 1995. Helsinki: Statistics Finland.

Brockett, R.; Hiemstra, R. (1991). Self-Direction in Adult Education: Perspectives on Theory, Research and Practice. New York: Routledge.

Brookfield, S. (1981). The Adult Education Learning Iceberg. Adult Education (UK). 54, 2; pp. 110-118.

CEDEFOP (2005). The Learning Continuity: European Inventory on Validating Non-formal and Informal Learning - National Policies and Practices in Validating Non-formal and Informal Learning, CEDEFOP Panorama Series 117, Luxembourg. Obtenido en: http://www.cedefop. europa.eu/EN/Files/5164_en.pdf

CEDEFOP (2008). Terminology of Education and Training Policy. A selection a 100 key terms Tissot P. (ed.), CEDEFOP Office for Official Publications of the European Communities, Luxembourg. Obtenido en: http://www. cedefop.europa.eu/en/Files/4064_EN.PDF

Coombs, P.H.; Prosser, C.; Ahmed, M. (1973). New Paths to Learning for Rural Children and Youth, New York: International Council for Educational Development.

Coombs P.H.; Ahmed, M. (1974). Attacking Rural Poverty: How Non-formal Education Can Help, Johns Hopkins University Press.

European Commission (2000). Memorandum on Lifelong Learning, SEC (2000) 1832. Obtenido en: http://www.bologna-berlin2003.de/pdf/ MemorandumEng.pdf

Eraut, M. (2000). Non-formal learning and tacit knowledge in professional work. British Journal of Educational Psychology; 70, pp., 113-136.

EUROSTAT (2001). Measuring Lifelong Learning, Task Force Report (TF/MLLL), Spyridon Pilos, Education and Training Statistics, March. Eurostat Working Papers, Population and Social Conditions 3/2001/E/Nº4.

EUROSTAT (2006). Classifications for Learning Activities: Manual, Education, Science and Culture Statistics, Population and Social Conditions 3/2006/F/No31, EUROSTAT/F-4. Obtenido en: http://forum.europa. eu.int/Public/irc/dsis/edtcs/library?l=/public/measuring_lifelong/class ificationsyvm=detailedysb=Title

ISCED (1997). International Standard Classification of Education. UNESCO. Obtenido en: http://www.unesco.org/education/information/ nfsunesco/doc/isced_1997.htm

Johnstone, J.; Rivera, R. (1965). Volunteers for Learning: A Study of the Educational Pursuits of American Adults. Chicago: Aldine. 
Knowles, M. (1970). The modern practice of adult education: Andragogy versus pedagogy. Chicago: Follett.

Livingstone, D.W. (1999). Exploring the Icebergs of Adult Learning: Findings of the First Canadian Survey of Informal Learning Practices. Canadian Journal for the Study of Adult Education. 13, 2, pp. 49-72.

Livingstone, D. W. (2000). Exploring the Icebergs of Adult Learning: Findings of the First Canadian Survey of Informal Learning Practices, NALL, Working Paper n. ${ }^{\circ} 10-2000$. Obtenido en: www.oise.utoronto.ca/depts/sese/ csew/nall/res/10exploring.htm

Livingstone, D.W. (2001). Adults' Informal Learning: Definitions, Findings, Gaps and Future Research, NALL Working Paper n. ${ }^{\circ} 21$ 2001. Obtenido en: www.oise.utoronto.ca/depts/sese/csew/nall/ res/2ladultsifnormallearning.htm

New Approaches to Lifelong Learning-NALL. (1998). Lifelong Learning Profiles: General Summary of Findings from the First Canadian Survey of Informal Learning. Obtenido en: http://www.nall.ca/sur_res.htm

OCDE (2007a). Terms, concepts and models for analysing the value of recognition programmes, EDU/EDPC (2007) 24. Obtenido en: http:// www.oecd.org/dataoecd/33/58/41834711.pdf

OCDE (2007b). Qualifications Systems: Bridges to Lifelong Learning, OCDE, Paris.

OCDE (2010). Recognising non-formal and informal learning outcomes. Policies and practices. Obtenido en: http://www.oecd.org/dataoecd/2/53/45007044. pdf

Penland, P. (1977). Self-Planned Learning in America. Pittsburgh: University of Pittsburgh.

Schugurensky, D. (2000). The Forms of Informal Learning: Towards a Conceptualization of the Field, NALL Working Paper n. ${ }^{\circ} 19$ 2000. Obtenido en: www.oise.utoronto.ca/depts/sese/csew/nall/ res/19formsofinformal.htm

Strauss, A. L.; Corbin, J. (1990). Basics of qualitative research: Grounded theory procedures and techniques. Newbury Park, CA: Sage.

Tough, A.M. (1971). The adult's learning projects. Toronto: Ontario Institute for Studies in Education.

Tough, A.M. (1979). The Adult's Learning Projects: A Fresh Approach to Theory and Practice in Adult Learning. Toronto: OISE Press.

Tough, A.M. (2002). The Iceberg of Informal Adult Learning, NALL Working Paper n. ${ }^{\circ}$ 49-2002. Obtenido en: http://www.nall.ca/res/49AllenTough.pdf 
184 ESTUDIO EXPLORATORIO SOBRE APRENDIZAJE NO FORMAL E INFORMAL DE ESTUDIANTES Y EGRESADOS UNIVERSITARIOS - R. Carrasco, F. Jadue, M. Letelier, C. Oliva

Werquin, P. (2007). Moving Mountains: Will Qualifications Systems Promote Lifelong Learning? European Journal of Education, 42(4), pp. 459-484.

Werquin, P. (2008). Recognition of non-formal and informal learning in OECD countries: A very good idea in jeopardy? Obtenido en: http://www.oecd. org/dataoecd/9/16/41851819.pdf

Recibido: 16/03/2011

Aceptado: 14/05/2012 